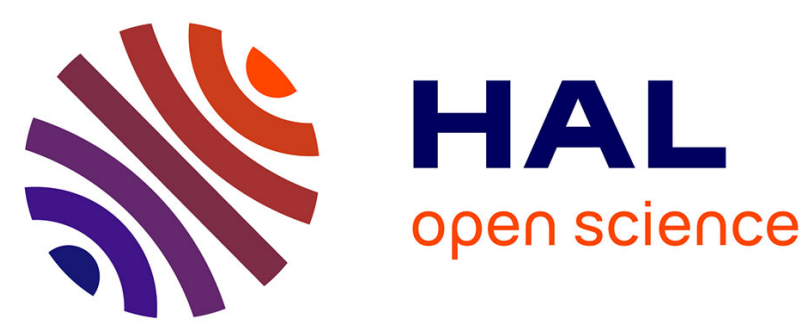

\title{
Tuning Complex Shapes in Platinum Nanoparticles: From Cubic Dendrites to Fivefold Stars
}

Lise-Marie Lacroix, Christophe Gatel, Raul Arenal, Cécile Marcelot, Sébastien

Lachaize, Thomas Blon, Bénédicte Warot-Fonrose, Etienne Snoeck, Bruno

Chaudret, G. Viau

\section{To cite this version:}

Lise-Marie Lacroix, Christophe Gatel, Raul Arenal, Cécile Marcelot, Sébastien Lachaize, et al.. Tuning Complex Shapes in Platinum Nanoparticles: From Cubic Dendrites to Fivefold Stars. Angewandte Chemie International Edition, 2012, 51 (19), pp.4690-4694. 10.1002/anie.201107425 . hal-03156608

\section{HAL Id: hal-03156608 https://hal.science/hal-03156608}

Submitted on 2 Mar 2021

HAL is a multi-disciplinary open access archive for the deposit and dissemination of scientific research documents, whether they are published or not. The documents may come from teaching and research institutions in France or abroad, or from public or private research centers.
L'archive ouverte pluridisciplinaire HAL, est destinée au dépôt et à la diffusion de documents scientifiques de niveau recherche, publiés ou non, émanant des établissements d'enseignement et de recherche français ou étrangers, des laboratoires publics ou privés. 


\title{
Tuning complex shapes in $P t(0)$ nanoparticles : from cubic dendrites to five-fold stars
}

\author{
Lise-Marie Lacroix, Christophe Gatel, Raul Arenal, Cécile Garcia, Sébastien Lachaize, Thomas Blon, \\ Bénédicte Warot-Fonrose, Etienne Snoeck, Bruno Chaudret and Guillaume Viau
}

Synthesis of nanoparticles (NPs) exhibiting large surface-area-tovolume ratio has been a long-sought goal in developing various applications such as ultra-sensitive sensors ${ }^{1}$ or highly active catalysts. $^{2}$ In addition to a large specific area, crystallographic planes exposed on the surface of the NPs are key parameters for the reactivity and selectivity of NPs in catalytic processes. ${ }^{3}$ Thus, intense researches have been devoted to the shape control of noblemetal nanocrystals. ${ }^{4}$ For instance for $\mathrm{Pt}$ based nanoparticles, dendritic nanostructures, ${ }^{5}$ branched-NPs, ${ }^{6}$ or multipods ${ }^{7}$ exhibit enhanced catalytic activities compared to their spherical counterparts. ${ }^{8}$ Such shape control could be obtained by manipulating the reduction kinetics ${ }^{6}$ through temperature $,{ }^{6 a, 9} \mathrm{pH},{ }^{10}$ ligands, ${ }^{11}$ or addition of small amounts of nucleating agents. ${ }^{6 \mathrm{~b}}$ Interestingly, in this variety of shapes, only few groups reported multiply-twinned $\mathrm{Pt}$ nanoparticles ${ }^{12}$ while decahedrons are fairly common for most of the noble metals ( $\mathrm{Au}, \mathrm{Ag}, \mathrm{Rh} . ..) .{ }^{13}$ However, these twinned NPs could offer significant benefits toward catalysis due to $\{111\}$ faces mainly exposed. ${ }^{14}$

Herein we report complex platinum nanoobjects of unprecedented shapes (monodisperse cubic dendrites and five-fold stars) and the fine tuning between two growth mechanisms. The platinum concentration is finely tuned in a fairly simple reaction of $\mathrm{H}_{2} \mathrm{PtCl}_{6}$ in oleylamine under dihydrogen pressure. Amine plays the role of solvent, stabilizer and can assist the reduction process. Previous work has shown that the room temperature reduction of $\mathrm{HAuCl}_{4}$ by neat oleylamine yielded unique $\mathrm{Au}$ nanowires. ${ }^{15}$ However, in the same conditions, $\mathrm{Pt}$ required higher temperature to be reduced $\left(250^{\circ} \mathrm{C}\right) .{ }^{9}$ In the present study, addition of dihydrogen, a well-known reducing agent, ${ }^{16}$ lowered the reduction temperature and, in the same time, played an important role in the shape control of NPs. Indeed, $\mathrm{H}_{2}$ can "clean" the NP surface by temporarily removing weak coordinating ligands such as amines, leading to

[*] Dr. L.-M. Lacroix, Dr. C. Garcia, Dr. S. Lachaize, Dr. T. Blon, Pr. B. Chaudret, Pr. G. Viau

LPCNO, Université de Toulouse, INSA, UPS, CNRS

135 avenue de Rangueil, F-31077 Toulouse (France)

Fax: (+)33.5.61.55.96.97

E-mail: Imlacroi@insa-toulouse.fr

Homepage http://lpcno.insa-toulouse.fr/

Dr. C. Gatel, Dr. B. Warot-Fonrose, Pr. E. Snoeck CEMES, CNRS

29 rue Jeanne Marvig, F-31077 Toulouse (France)

Dr. R. Arenal

Laboratorio de microscopias avanzadas (LMA), Instituto de Nanociencia de Aragon (INA), U. Zaragoza, C/ Mariano Esquillor s/n, 50018 Zaragoza (Spain)

Fundacion ARAID, 50004 Zaragoza, Spain

[**] This work was supported by the European FP7-Train2 project and the French network METSA. We thank G. Antorrena for XPS measurements.

Supporting information for this article is available on the WWW under http://www.angewandte.org or from the author. coalescence or ripening. ${ }^{17} \mathrm{H}_{2}$ can also generate surface hydrides which stabilize the NP and perform hydrogenation reactions. ${ }^{18}$

An ex-situ kinetic study, followed by High Resolution Transmission Electron Microscopy (HRTEM), has evidenced two growth mechanisms based respectively on cubic or decahedric seeds (cf Scheme 1) leading to monodisperse cubic dendrites or five-fold stars.

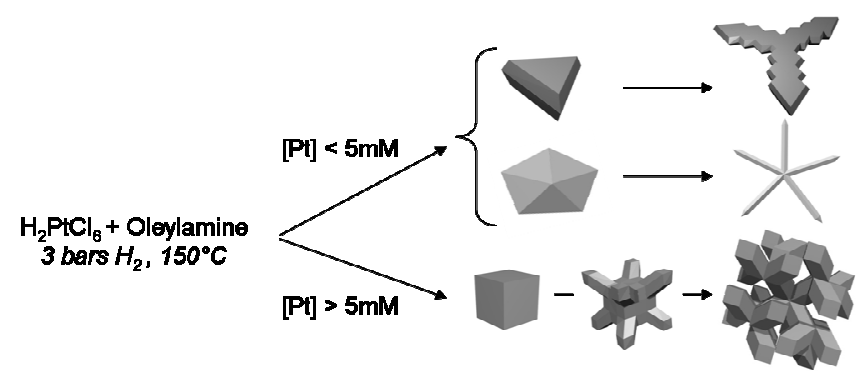

Scheme 1. General overview of the versatile synthesis of $\operatorname{Pt}(0)$ NPs. Shape could be controlled by the platinum concentration, and the nature of the seeds formed.

Pt NPs were produced by reduction of $\mathrm{H}_{2} \mathrm{PtCl}_{6}$ in oleylamine under an $\mathrm{H}_{2}$ atmosphere (3 bars) at $150^{\circ} \mathrm{C}$ (Experimental Section, Scheme 1). The shape of Pt NPs could be easily tuned by varying the experimental parameters, in particular the Pt concentration from low $(2 \mathrm{mM})$ to high $(10 \mathrm{mM})$ values. For instance, a dendritic growth was observed at high $\mathrm{Pt}$ concentration $([\mathrm{Pt}]>5 \mathrm{mM})$ (Figure 1a-b, S1 and S2). The resulting objects were obtained quantitatively with a Pt yield over $95 \%$. The most striking feature, compared to previously reported dendrites, ${ }^{5}$ was their cubic contour.
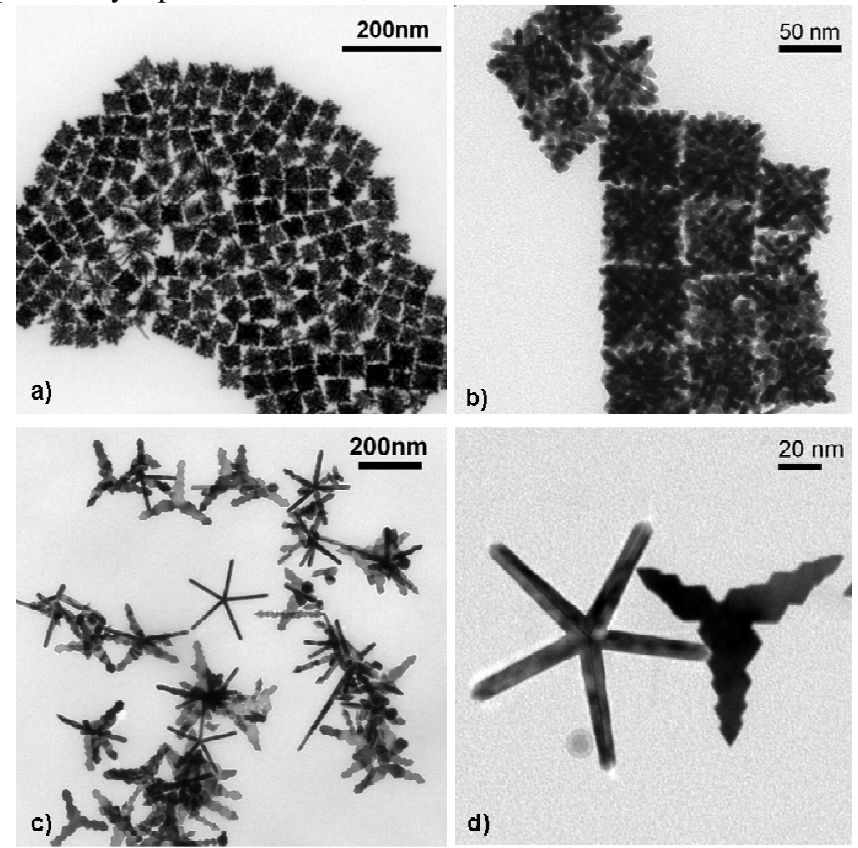

Figure 1. TEM images of $\mathrm{Pt}$ nanocrystals prepared at different concentrations of platinum (a-b) dendritic cubes obtained for $[\mathrm{Pt}]=$ $10 \mathrm{mM}$, (c-d) Pt stars obtained at $[\mathrm{Pt}]=2 \mathrm{mM}$. 

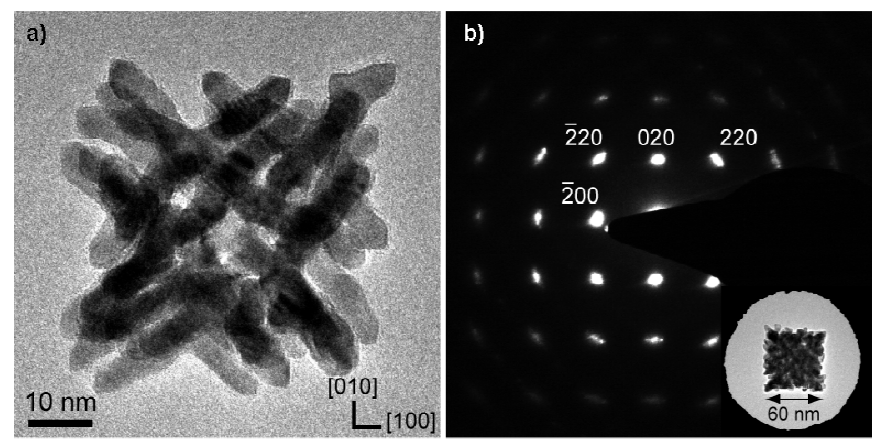

Figure 2. (a) HREM image of a single Pt dendritic cube obtained after $1 \mathrm{~h}$ of reaction. (b) Selective Area Electron Diffraction (SAED) along [001] axis on a $60 \mathrm{~nm}$-cube obtained after $2 \mathrm{~h}$ of reaction, as shown in the inset.

Figure 2 shows a high-magnification Transmission Electron Microscopy (TEM) image of a single dendrite exhibiting a dense organization of branches with defined orientations. Outer faces of the cubes coincided with $\{100\}$ planes of the crystallographic structure of fcc-Pt. Selective Area Electron Diffraction (SAED) pattern on a single cube (Figure $2 \mathrm{~b}$ ) shows a fourfold symmetry, characteristic of a single-crystalline fcc-crystal observed along the $<100>$ zone axis. The elongation of the diffraction spots $\{200\}$ and $\{220\}$ indicates a slight misorientation between the branches $(\mathrm{ca}$ $10^{\circ}$ ). These results demonstrate that cubic dendrites adopt a singlecrystalline structure slightly distorted.

The growth mechanism of such peculiar dendrites has been investigated by stopping the reaction at different stages (Figure 3 and S3). The reaction is very fast as shown by the octapods already observed after $1 \mathrm{~min}$ of reaction at $150^{\circ} \mathrm{C}$. These octapods result from a growth on $<111>$ directions on cubic seeds. $\{100\}$ facets are observed, concomitant with closing $\{110\}$ facets. After 3 minutes of reaction, the selected growth on $\{100\}$ facets leads to the appearance of bifurcations, new branches start to grow along 3 different $\langle 111\rangle$ growth directions. Such a selected growth is repeated until the total consumption of the platinum precursor. While the diameter of the branches was rather constant at $c a .5 .5 \mathrm{~nm}$, the mean size of the cubic dendrites could be tuned from 30 to 100 $\mathrm{nm}$ by varying the reaction time between $10 \mathrm{~min}$ and $2 \mathrm{~h}$ (Figure S4). The dendrites finally obtained, exhibit a high proportion of $\{100\}$ and $\{110\}$ facets, as in the earlier growth stage (Figure S5). Such dendritic structures, which have no precedent, were stable at $150^{\circ} \mathrm{C}$ for days, the complex branches architecture did not collapse into denser crystals.

At low Pt concentration $([\mathrm{Pt}]=2 \mathrm{mM})$, star-shaped NPs were obtained (Figure 1c-d and S6). Samples were composed of nanocrystals exhibiting a well-defined morphology with $\sim 20 \%$ of 5 -fold stars, $\sim 70 \%$ of 3 -fold stars (planar tripods) and $\sim 10 \%$ of multipods or undefined shapes. This ratio could vary: the proportion of multipods increased with the [Pt] concentration. 3-fold stars, have previously been obtained using a different approach (reduction of $\mathrm{Pt}(\mathrm{acac})_{2}$ by a diol at $\left.160^{\circ} \mathrm{C}\right)^{7 \mathrm{a}}$. However, the present 5 -fold Pt stars are unique. Their arm length could be tuned from $30 \mathrm{~nm}$ to $120 \mathrm{~nm}$ by varying the reaction time between 6 and 48h (Figure S7).

Figure 4 shows a high magnification image of a single 5 -fold star and the corresponding SAED pattern along the $<110>$ zone axis. The complex pattern displays a 5-fold symmetry of the fcc structure spots, similar to the SAED pattern obtained on Au decahedra. ${ }^{19}$ HRTEM image of the core clearly shows the non-crystallographic five-fold axis and the five resulting twinning boundaries. Periodic lattice fringes could be clearly resolved for 3 families of planes.
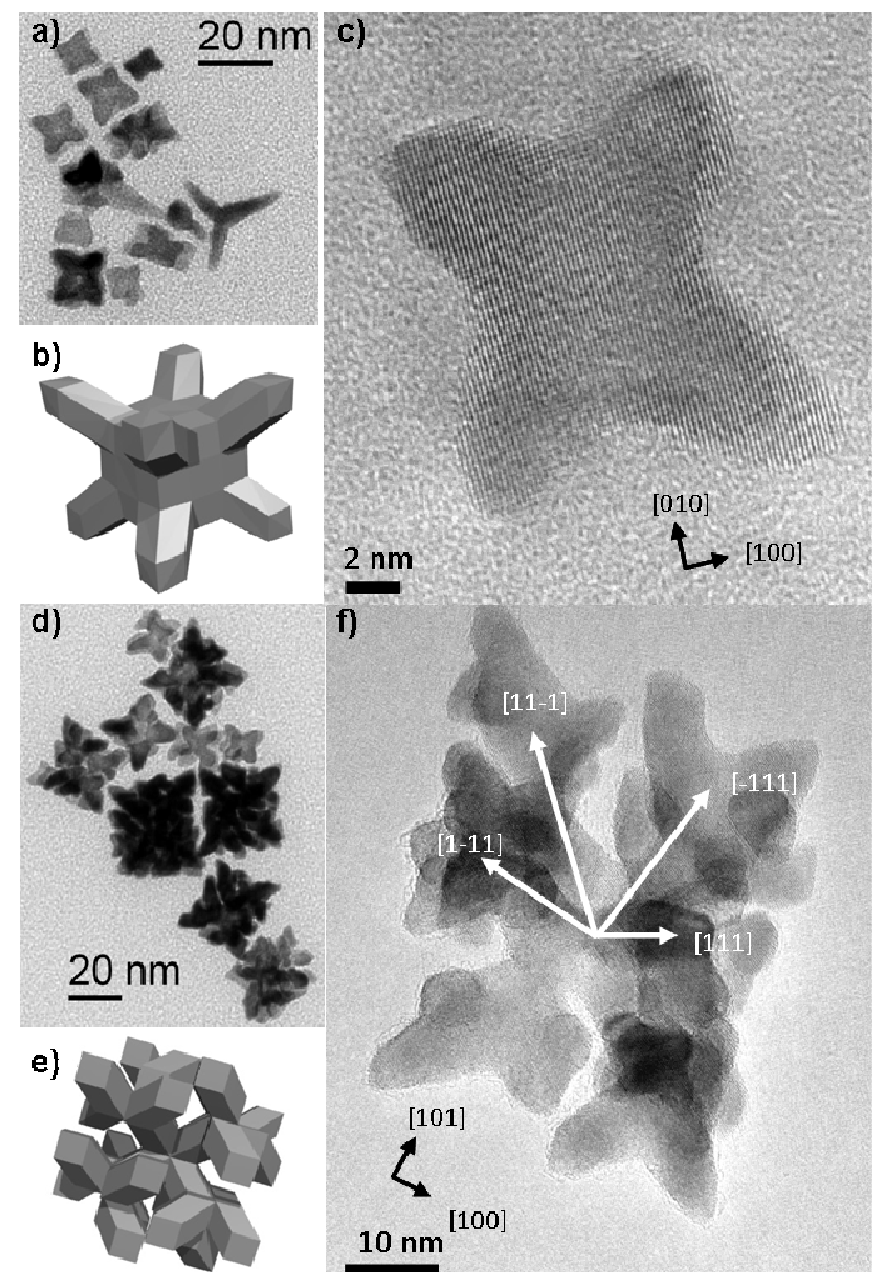

f)

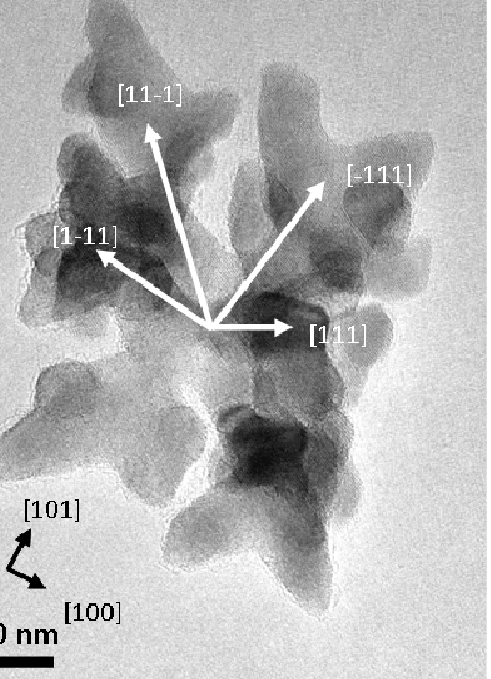

Figure 3. Nanoparticles obtained after (a-c) $1 \mathrm{~min}$ and (d-f) 3 min of reaction. (a, d) TEM micrograph and the corresponding (c, f) HREM micrographs. $\{100\}$ facets are highlighted along the $<111>$ growth directions. (b, e) are schematic view of the objects at this growth stage.

Lattice spacings of $2.26 \AA$ and $1.96 \AA$ correspond to the $\{111\}$ and $\{100\}$ planes of fcc-Pt respectively. The rotation of these planes along the five-fold axis is evidenced on Figure 4c: single-crystalline tetrahedra were observed between two successive twin-boundaries.

Figure $4 \mathrm{~d}$ shows a HRTEM image of the branch tip. The branches are highly crystalline, exposing mainly $\{111\}$ facets (Figure S8-10). These branches grow symmetrically along the twinning plane, from each corner of the central decahedra as revealed by TEM images taken after different growth stages (Figure 5). Such a growth on decahedra corners has been recently reported by Zhang et al. on Rh star-fish like NPs, but the crystallinity of the branches was not clearly evidenced. ${ }^{13 \mathrm{c}}$ If Pt decahedra are fairly rare objects, highly crystalline five-fold Pt stars represent a unique result to the best of our knowledge.

X-ray Photoelectron Spectroscopy (XPS) and Energy Dispersive X-ray Spectroscopy (EDS) analyses have been performed on cubic dendrites and stars. As expected, the Pt NPs resulting from the different syntheses consisted of pure $\mathrm{Pt}(0)$ (Figure S11-12). The surface of the particles was stabilized mostly by amine groups, although chloride anions and ammonium groups could be detected as traces. 
It is noteworthy that reaction times were considerably expanded at low $[\mathrm{Pt}]$ concentration compared to the few minutes required for high $[\mathrm{Pt}]$ concentration synthesis. At $2 \mathrm{mM}$, the yellowcolour, characteristic of the Pt precursor, vanished after at least $24 \mathrm{~h}$ of reaction. The shape control in this versatile synthesis looked then strongly correlated to the reaction rates. Three experimental parameters can be adjusted to quicken the reaction kinetic: $[\mathrm{Pt}]$ concentration, temperature $(T)$ and dihydrogen pressure $\left(p_{\mathrm{H} 2}\right)$. Increasing the temperature and pressure yield cubic dendrites after only 1 hour (Figure S13) even at low $[\mathrm{Pt}]$ concentration $(2 \mathrm{mM})$. Thus, we could induce a dendritic growth by fastening the reaction kinetic. An illustration of this difference of kinetic between cubic dendrites and stars is given by the variation of dihydrogen pressure profile with time (Figure S14). A fast consumption of dihydrogen was observed for dendritic growth, while no abrupt drop was detected in the case of star-shape growth. These two hydrogenation profiles combine multiple reactions (reduction of platinum, corresponding to $\mathrm{ca}$. 0,3 bars of $\mathrm{H}_{2}$, and hydrogenation catalysed by Pt NPs and/or molecular species) in different experimental conditions. Thus the catalytic activities of dendrites vs. stars cannot be directly compared. However, we can conclude that very catalytically active species were quickly formed at high temperature and pressure, while this was not the case under lower conditions.
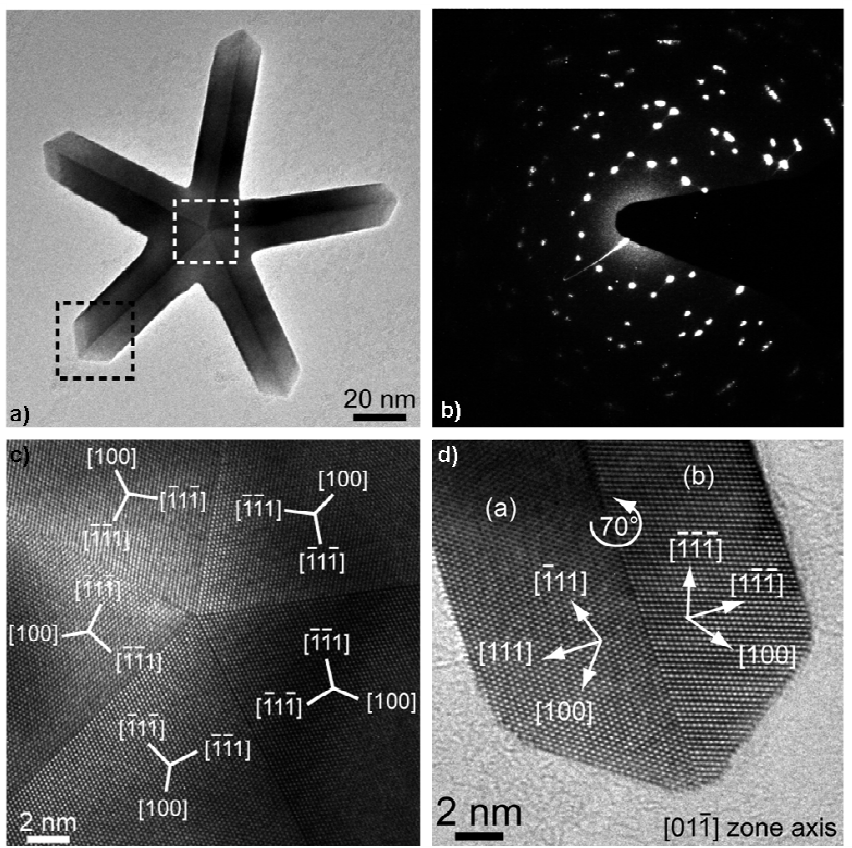

Figure 4. (a) TEM micrograph of a single Pt 5-fold star and (d) its corresponding ED pattern. HRTEM images of (c) the core and (d) a branch tip as shown in figure (a) by respectively white and black boxes.
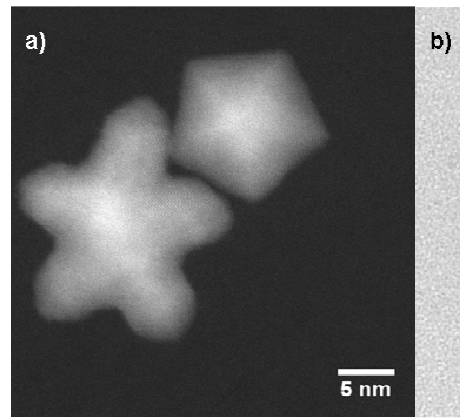

Figure 5. High Angle Annular Dark Field and TEM images of Pt NPs obtained for $[\mathrm{Pt}]=2 \mathrm{mM}$ at a) $2 \mathrm{~h}$ and b) $4 \mathrm{~h}$ of reaction.
The shape control reported here for $\mathrm{Pt}(0) \mathrm{NPs}$ (planar tripods, five-fold stars and cubic dendrites) is achieved by playing with the reaction conditions in a relatively narrow range of concentration or temperature. The nature of the seeds, cubic, exposing non compact faces, or triangular and decahedric, exposing $\{111\}$ faces, is determinant in the final morphology reached (Scheme 1).

At fast reaction rates, cubic seeds, exhibiting fcc structure, are quickly formed as shown by ex-situ HREM study and the evolution of $\mathrm{H}_{2}$ pressure as a function of time. The very fast consumption of $\mathrm{H}_{2}$ is due to a fast reduction of $\mathrm{Pt}$ precursor and to the hydrogenation of oleylamine by reactive seeds. Non compact faces $(\{100\}$ and $\{110\})$ are known to be active towards the reduction of internal olefins for $\mathrm{Pd}^{20}$ These cubic seeds, though very reactive, are relatively limited in numbers. The stability of $\mathrm{H}_{2} \mathrm{PtCl}_{6}$ precursor is indeed a determinant factor in this dendritic growth. The reduction of $\mathrm{Pt}(\mathrm{acac})_{2}$ under similar conditions yielded multiple seeds and thus multiarmed NPs (Figure S15). Few seeds and a fast reduction is characteristic of an auto-catalytic process, previously reported for $\mathrm{Pt}^{3}$ Such auto-catalytic process combines a surface reaction between the precursor and preferential faces, leading here to a growth direction along $<111>$ directions. The outer cubic shape of these nearly single-crystalline cubic dendrites, so peculiar, results from the strong crystallographic driving force combined with the tendency of dihydrogen to repair surfaces. The large cubic dendrites obtained at the end of the reaction expose non compact faces, which are not energetically favoured. Such structures represent kinetic products and result from a growth limited by the diffusion of adatoms at the surface. Such diffusion-limited process is also known to be responsible for the size monodispersity of the final objects. ${ }^{21}$

When the reaction rates were decreased, via the platinum concentration or via the lowering of the reaction temperature, the reduction of the platinum precursor occurred during a longer period of time and yield seeds exhibiting compact $\{111\}$ faces. The profile of dihydrogen consumption is drastically modified compared to dendritic growth, due to the formation of a very limited number of seeds and to their nature. Indeed, under these conditions, stable twinned decahedra or triangular seeds could grow, resulting from the minimization of surface energy. These objects expose only $\{111\}$ compact crystallographic planes. The successive growth of decahedra seeds into 5-fold stars could be explained via multiple nucleation events. Decahedra are composed of 5 tetrahedra. However, these tetrahedra cannot fill the entire space and leave an empty angle of $7,3^{\circ}$, unless they adopt a highly strained structure as reported for Au decahedra. ${ }^{19}$ Since strain increases with the particle size, above a critical size, corresponding to the highest strain in $\mathrm{Pt}$ decahedron, the structure relaxes. In our case, this relaxation corresponds to the nucleation and growth of the arms at each corner of the decahedra core (Figure 5). Further crystallographic studies will be performed on these 5-fold stars to determine the structural strain contained at the vicinity of the core and of the arms to confirm our growth model hypothesis. Such multi-step process has already been proposed by Maksimuk et al. ${ }^{7 a}$ for the growth of planar tripods. According to their model, branches grow at the corner of triangular twinned seeds, which act as preferential nucleation sites for a second growth process. In our reaction, five-fold stars and planar tripods coexist, giving strength to our growth hypothesis.

In summary, we have demonstrated that quasi singlecrystalline Pt nanoparticles with peculiar morphologies -cubic dendrites, planar tripods and 5-fold stars-, can be obtained selectively and in high yield from a very simple procedure by tuning 
the reduction kinetics of a platinum salt under a dihydrogen atmosphere in presence of an amine. The control of experimental parameters such as $\mathrm{Pt}$ concentration, reaction temperature and dihydrogen pressure, leads to a fine tuning of the kinetics of the reaction and of the nature of seeds formed during the nucleation step. Though, the reason for such an abrupt transition between cubic or twinned seeds is still unknown, numerical simulations of the energy of the seeds could give us some important highlights.

A slow reaction leads to twinned seeds which evolve into planar tripods (3-fold stars) and 5-fold stars. Such multiply twinned NPs are unique for $\mathrm{Pt}$ and could open new perspectives for fundamental research on strained materials. In addition to this fundamental interest, catalytic activities could benefit from the presence of almost exclusively crystallographic surface orientation $\{111\}$ for selectivity purposes.

A fast reaction leads to cubic seeds and thus to a dendritic growth. The peculiarity of these objects is their outer cubic shape and an unprecedented size control of their envelope. Such dendritic cubes display a high surface-to-volume ratio, while their cubic shape enables their self-assembly on surfaces which should be of high interest in catalysis. Structural characterization of the exposed surfaces, reactivity and catalytic activity of these novel species will be evaluated to attest the potential of these unique cubic dendrites.

\section{Experimental Section}

Typical synthesis of dendritic NPs : $\mathrm{H}_{2} \mathrm{PtCl}_{6}$ (Alfa Aesar, $51 \mathrm{mg}$, $0,1 \mathrm{mmole}$ ) and oleylamine (Aldrich, $10 \mathrm{~mL}$ ) were mixed in a vial, and placed $15 \mathrm{mn}$ in an ultrasonic bath to dissolve the Pt precursor. The $10 \mathrm{mM}$ solution was transferred in a Fisher-Porter bottle and pressurized up to 3 bars of $\mathrm{H}_{2}$. The bottle was then let to react at $150^{\circ} \mathrm{C}$ in a pre-heated oil bath for 1 hour. At the end of the reaction, a black precipitate was obtained while the supernatant is transparent Typical yellow-coloured Pt precursor traces were no longer observed. The bottle was then cooled down to room temperature, resulting in a solidification of the supernatant. $40 \mathrm{~mL}$ of hexanes (Aldrich) was added to solubilise the NPs. The suspension, after the addition of $40 \mathrm{~mL}$ of absolute ethanol (VWR), was then centrifugated (4000rpm, $6 \mathrm{~min})$ to separate the NPs. The process is repeated 3 times to remove the excess of surfactants. The final product (ca. $25 \mathrm{mg}$ ) was kept in powder form or diluted in $5 \mathrm{~mL}$ Toluene (Carlo Erba) for further use.

Multiply-twinned NPs were synthesized by a similar procedure except that the Pt concentration was decreased below $5 \mathrm{mM}$. The reaction time was expended to $48 \mathrm{~h}$ since the reaction kinetic is drastically reduced.

Characterizations: Samples for TEM were prepared by depositing few drops of diluted solution on amorphous carbon coated cupper grid. Low resolution images were obtained with a JEOL-1400 microscope, operating at $120 \mathrm{kV}$. HRTEM images were obtained with a Tecnai F20 $(200 \mathrm{kV})$ equipped with a spherical aberration corrector. X-ray photoelectron spectra were recorded using a Kratos Analytical Limited Axis ultra limited system fitted with a microfocused monochromatic Al K $\alpha$ X-ray source (1486,6 eV, 12kV * 120W). The pass energy was set at $160 \mathrm{eV}$ and $20 \mathrm{eV}$ for the survey and the regions spectra respectively.

Received: ((will be filled in by the editorial staff))

Published online on ((will be filled in by the editorial staff))
Keywords: Platinum nanoparticles. Shape control. 5-fold twinned nanostars. Dendritic nanocubes. Decahedra.

[1] N. J. Wittenberg, C. L. Haynes, WIREs Nanomed. Nanobiotech. 2009, $1,237-254$

[2] a) R. J. White, R. Luque, V. L. Budarin, J. H. Clark, D. J. Macqarrie, Chem. Soc. Rev. 2009, 38, 481-494; b) E. Antolini, J. Perez, J. Mater. Sci. 2011, 46, 4435-4457

[3] J. Chen, B. Lim, E. P. Lee, Y. Xia, Nano Today 2009, 4, 81-95

[4] a) A. R. Tao, S. Habas, P. Yang, Small, 2008, 4, 310-325; b) T. K. Sau, A. L. Rogach, Adv. Mater. 2010, 22, 1781-1804;

[5] a)Y. Song, Y. Yang, C. J. Madforth, E. Pereira, A. K. Singh, H. Xu, Y. Jiang, C. J. Brinker, F. Van Swol, J. A. Schelnutt, J. Am. Chem. Soc. 2004, 126, 635-645; b) X. Zhong, Y. Feng, I. Lieberwirth, W. Knoll, Chem. Mater. 2006, 18, 2468-2471

[6] a) J. Ren, R. D. Tilley, Small 2007, 3, 1508-1512; b) J. Chen, T. Herricks, Y. Xia, Angew. Chem. Int. Ed 2005, 44, 2589-2592

[7] a) M. A. Mahmoud, C. E. Tabor, M. A. El-Sayed, Y. Ding, Z. L. Wang, J. Am. Chem. Soc. 2008, 130, 4590-4591; b) S. Sun, G. Zhang, D. Geng, Y. Chen, R. Li, M. Cai, X. Sun, Angew. Chem. Int. Ed. 2011, 50, 422-426.

[8] a) Z. Peng, H. Yang, Nano Today 2009, 4, 143-164; b) B. Lim, Y. Xia, Angew. Chem. Int. Ed. 2011, 50, 76-85

[9] H.-T. Zhang, J. Ding, G.-M. Chow, Langmuir 2008, 24, 375-378

[10] H. Lee, S. E. Habas, S. Kweskin, D. Butcher, G. A. Somorjai, P. Yang, Angew. Chem. Int. Ed. 2006, 45, 7824-7828

[11] M. R. Axet, K. Philippot, B. Chaudret, M. Cabié, S. Giorgio, C. R. Henry, Small 2011, 7, 235-241

[12] a) S. Maksimuk, X. Teng, H. Yang, J. Phys. Chem. C 2007, 111, 14312-14319; b) N. V. Long, M. Ohtaki, M. Uchida, R. Jalem, H. Hirata, N. D. Chien, M. Nogami, J. Coll. Inter. Sci. 2011, 359, 339350

[13] a) D. Seo, C. I. Yoo, I. S. Chung, S. M. Park, S. Ryu, H. Song, J. Phys. Chem. C 2008, 112, 2469-2475; b) W. Zhang, Y. Liu, R. Cao, Z. Li, Y Zhang, Y. Tang, K. Fan, J. Am. Chem. Soc. 2008, 130, 15581-15588; c) H. Zhang, X. Xia, W. Li, J. Zeng, Y. Dai, D. Yang, Y. Xia, Angew. Chem. Int. Ed. 2010, 49, 5296-5300

[14] a) A. Guerrero-Martinez, S. Barbosa, I. Pastoriza-Santos, L. M. LizMarzan, Curr. Op. Coll. Inter. Sci. 2011, 16, 118-127; b) H. Hofmeister, Z. Kristallogr. 2009, 224, 528-538

[15] a) Z. Huo, C.-K. Tsung, W. Huang, X. Zhang, P. Yang, NanoLett. 2008, 8, 2041-2044; b) X. Lu, M. S. Yavuz, H.-Y. Tuan, B. A. Korgel, Y. Xia, J. Am. Chem. Soc. 2008, 130,8900-8901

[16] a) F. Dumestre, B. Chaudret, C. Amiens, M. Respaud, P. Fejes, P. Renaud, P. Zurcher, Angew. Chem. Int. Ed. 2003, 42, 5213-5216 ; b) L.-M. Lacroix, S. Lachaize, A. Falqui, M. Respaud, B. Chaudret, $J$. Am. Chem. Soc. 2009, 131, 549-557 ; c) C. Desvaux, C. Amiens, P. Fejes, P. Renaud, M. Respaud, P. Lecante, E. Snoeck, B. Chaudret, Nature. Mater. 2005, 4, 750-753

[17] E. Ramirez, L. Eradès, K. Philippot, P. Lecante, B. Chaudret, $A d v$. Funct. Mater. 2007, 17, 2219-2228

[18] a) T. Pery, K. Pelzer, G. Buntkowsky, K. Philippot, H.-H. Limbach, B. Chaudret, Chem. Phys. Chem. 2005, 6, 605-607 ; b) J. Garcia-Anton, M. R. Axet, S. Jansat, K. Philippot, B. Chaudret, T. Pery, G. Buntkowsky, H.-H. Limbach, Angew. Chem. Int. Ed. 2008, 47, 20742078

[19] C. L. Johnson, E. Snoeck, M. Ezcurdia, B. Rodriguez-Gonazalez, I. Pastoriza-Santos, L. M. Liz-Marzan, M. J. Hÿtch, Nature Mater. 2008, 7, 120-124

[20] a) L. Piccolo, A. Valcarel, M. Bausach, C. Thomazeau, D. Uzio, G. Berhault, Phys. Chem. Chem. Phys. 2008, 10, 5504-5506; b) D. Uzio, G. Berhault, Catal. Rev. Sci. Eng. 2010, 52, 106-131

[21] J. Park, J. Joo, S. G. Kwon, Y. Jang, T. Hyeon, Angew. Chem. Int. Ed. 2007, 46, 4630-4660 


\section{Stars and dendrites}

L.-M. Lacroix, ${ }^{\star}$ C. Gatel, R. Arenal, C.

Garcia, , S. Lachaize, T. Blon, B. Warot-

Fonrose, E. Snoeck, B. Chaudret and G.

Viau

$$
\text { Page - Page }
$$

Access to complex shapes in $\operatorname{Pt}(0)$

nanoparticles: from cubic dendrites to five-fold stars

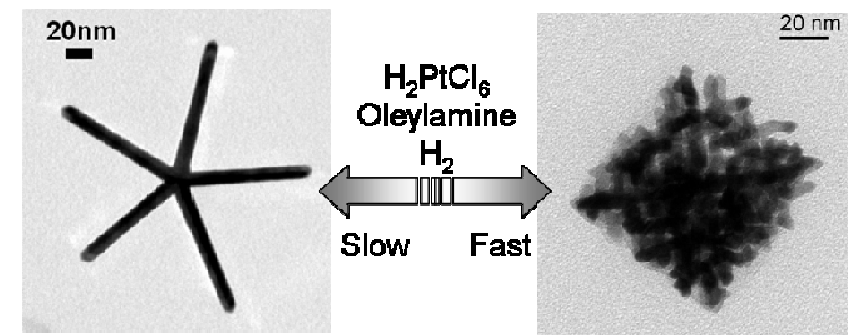

Quasi single-crystalline Pt nanoparticles with peculiar morphologies, cubic dendrites, planar tripods and 5-fold stars, can be synthesized selectively and in high yield by finely tuning the kinetics of an amine-based reaction under dihydrogen. 


\section{Supplementary Information}

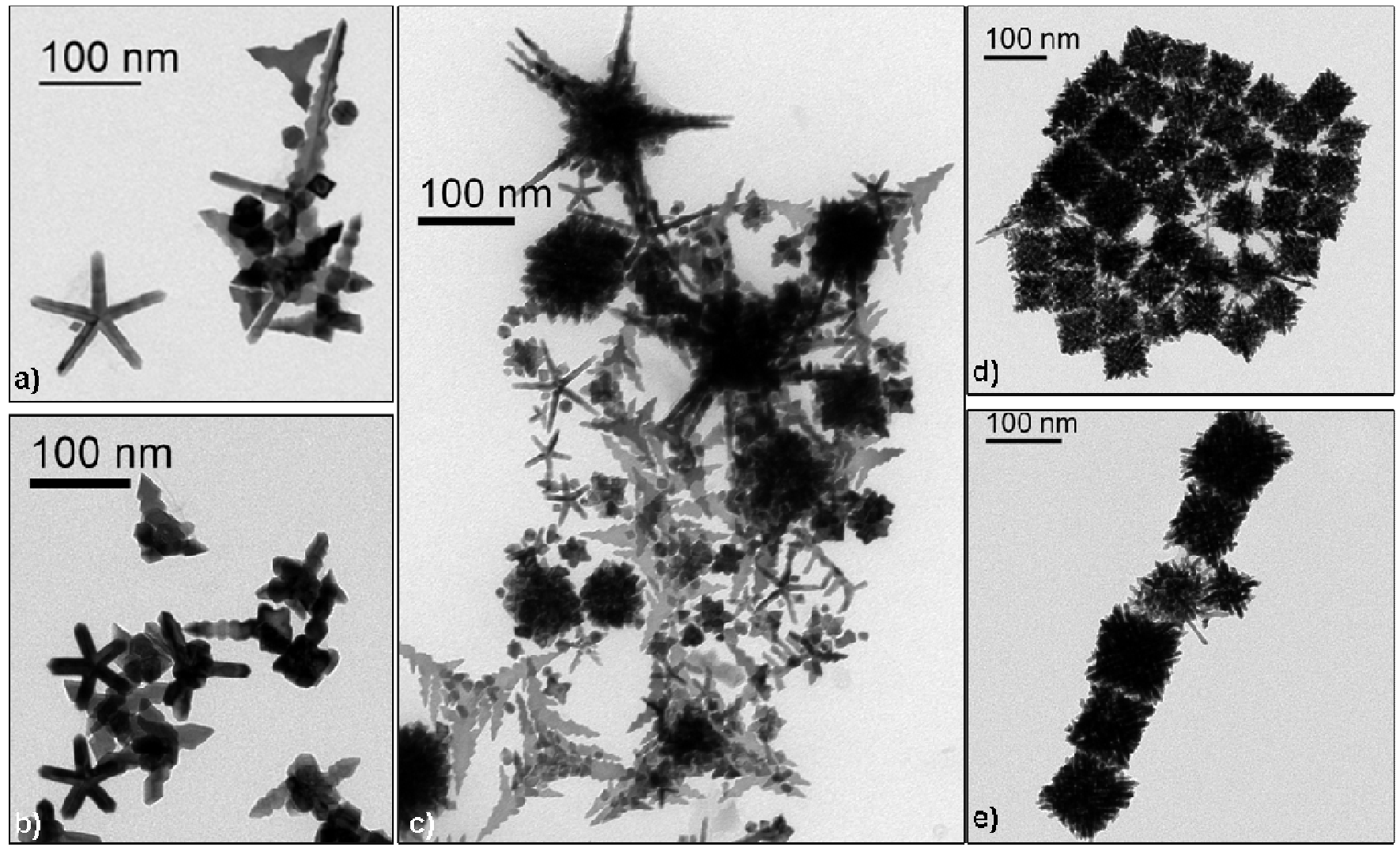

Figure S1 : TEM images of Pt nanoparticles finally obtained at $150^{\circ} \mathrm{C}, 3$ bars $\mathrm{H}_{2}$ for [Pt] of a) $0,5 \mathrm{mM}$, b) $2 \mathrm{mM}$, c) $5 \mathrm{mM}$, d) $6 \mathrm{mM}$ and e) $10 \mathrm{mM}$. At $5 \mathrm{mM}$ both dendrites and 5 -fold stars can be observed.
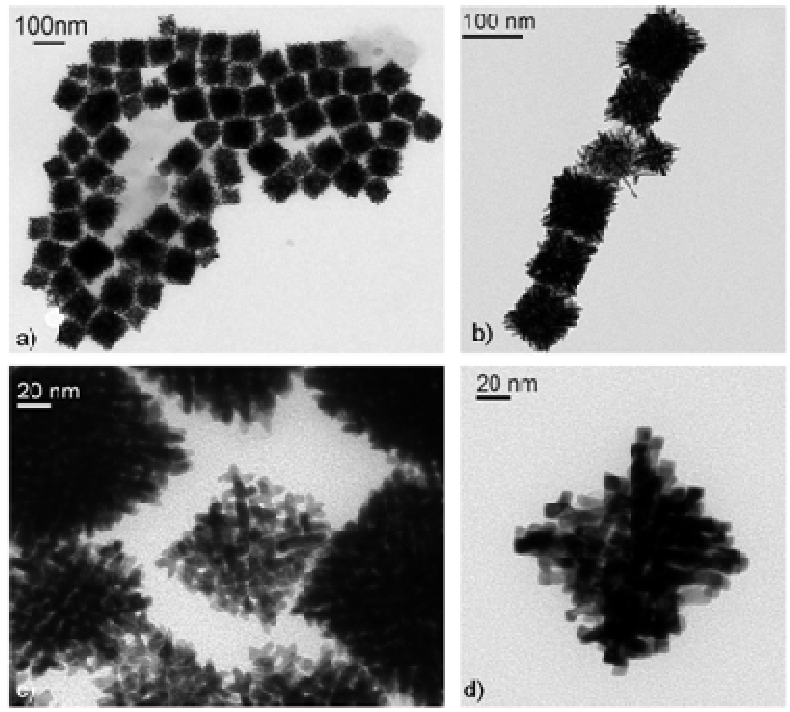

Figure S2 : TEM images of cubic dendrites obtained after $1 \mathrm{~h}$ of reaction at $150^{\circ} \mathrm{C}, 3$ bars $\mathrm{H}_{2},[\mathrm{Pt}]=10 \mathrm{mM}$ under different magnifications a) $12 \mathrm{k}$, b) $30 \mathrm{k}$, c) $80 \mathrm{k}$, c) $100 \mathrm{k}$ 

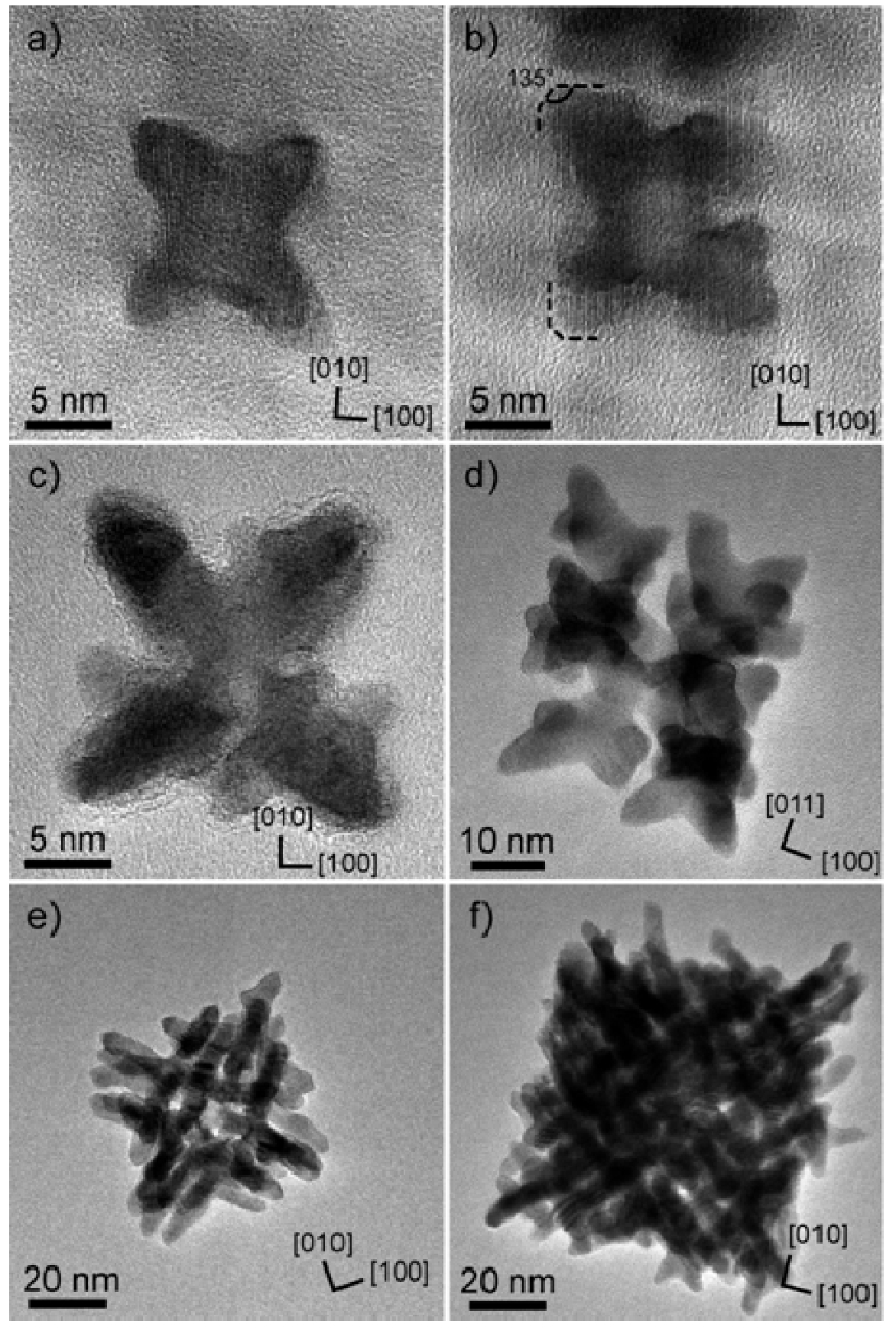

Figure S3 : HRTEM images of cubic dendrites obtained at $150^{\circ} \mathrm{C}, 3$ bars $\mathrm{H}_{2},[\mathrm{Pt}]=10 \mathrm{mM}$ after different reaction times : a-b) $1 \mathrm{~min}, \mathrm{c}-\mathrm{d}) 3 \mathrm{~min}, \mathrm{e}) 20 \mathrm{~min}$ and f) $60 \mathrm{~min}$ of reaction. 

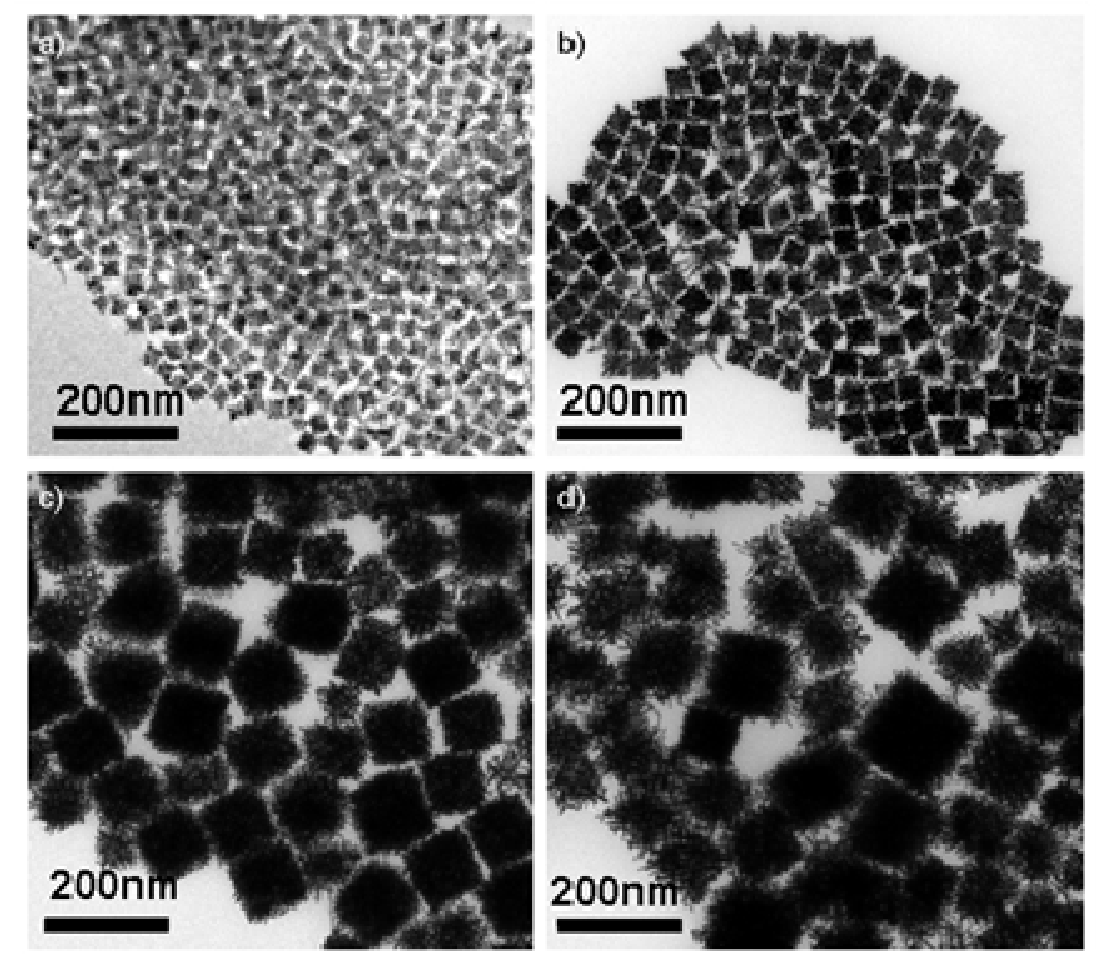

Figure $S 4$ : TEM images of cubic dendrites obtained at $150^{\circ} \mathrm{C}, 3$ bars $\mathrm{H}_{2},[\mathrm{Pt}]=10 \mathrm{mM}$ after different reaction times : a) $10 \mathrm{~min}$, b) $20 \mathrm{~min}, \mathrm{c}) 1 \mathrm{~h}$ and d) $6 \mathrm{~h}$ of reaction. 


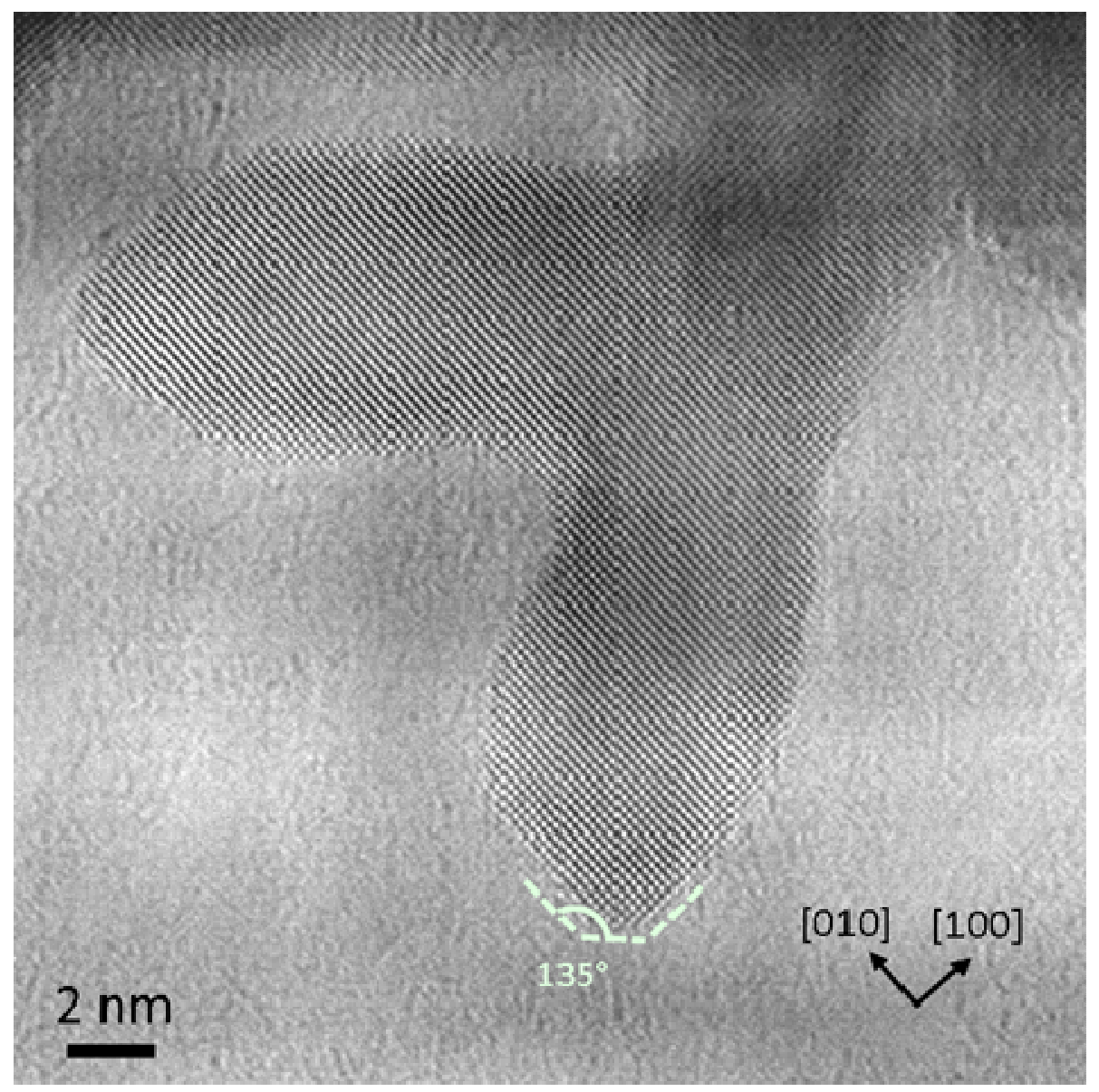

Figure S5 : HRTEM image of a detailed of a cubic dendrite obtained at $150^{\circ} \mathrm{C}, 3$ bars $\mathrm{H}_{2},[\mathrm{Pt}]=10 \mathrm{mM}$ after 60 min of reaction. 

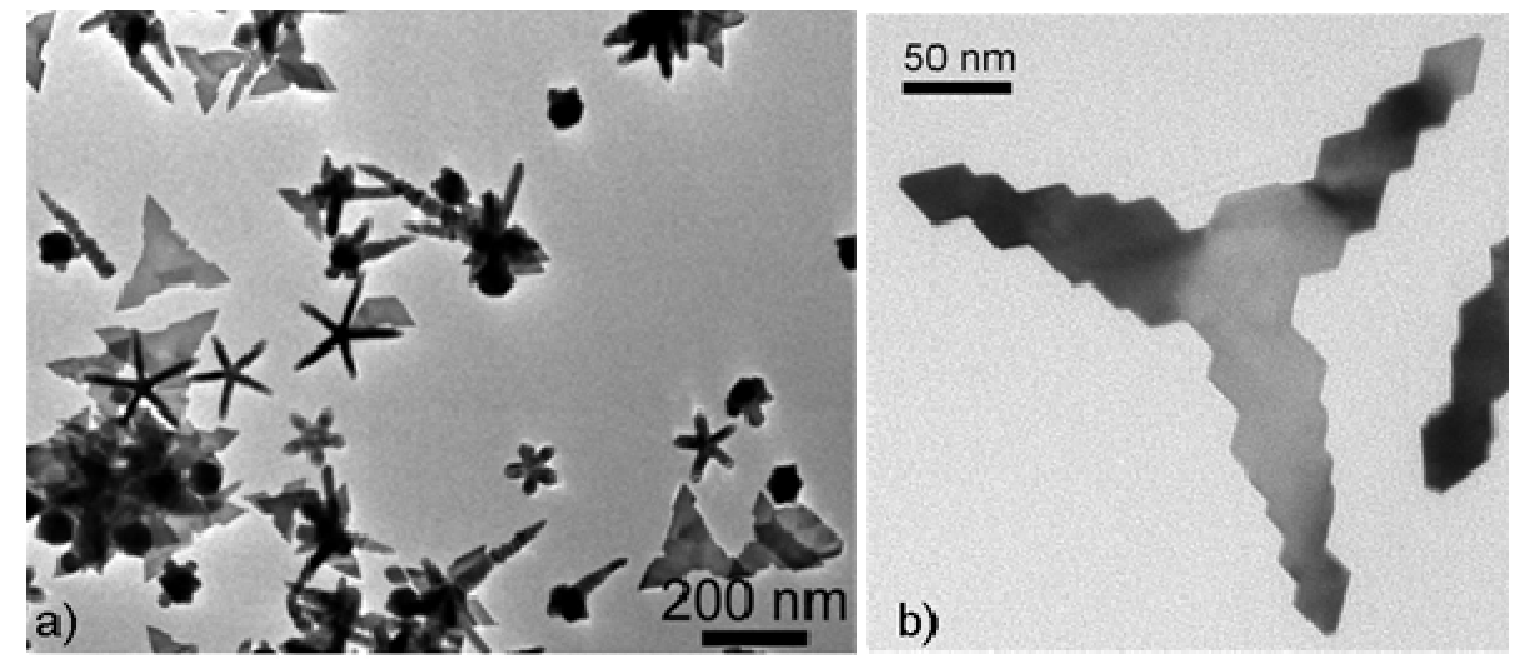

Figure S6 : TEM images of Pt NPs obtained after $32 \mathrm{~h}$ at $150^{\circ} \mathrm{C}, 3$ bars $\mathrm{H}_{2}$, $[\mathrm{Pt}]=2 \mathrm{mM}$. a) general view and high magnification images of b) 3-fold star.
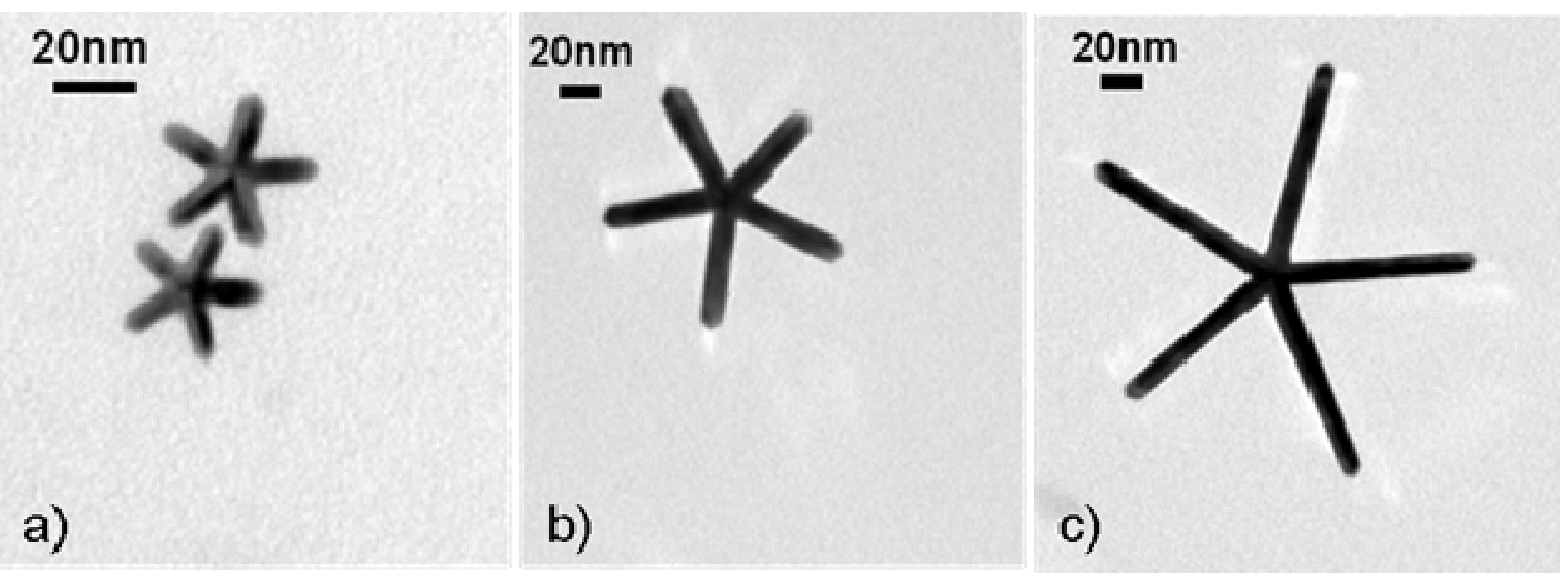

Figure S7 : TEM images of Pt NPs obtained for $[\mathrm{Pt}]=2 \mathrm{mM}$ after a) $6 \mathrm{~h}$, b) $24 \mathrm{~h}$ and c) $48 \mathrm{~h}$ of reaction at $150^{\circ} \mathrm{C}$ and $3 \mathrm{bars}$ of $\mathrm{H}_{2}$. 

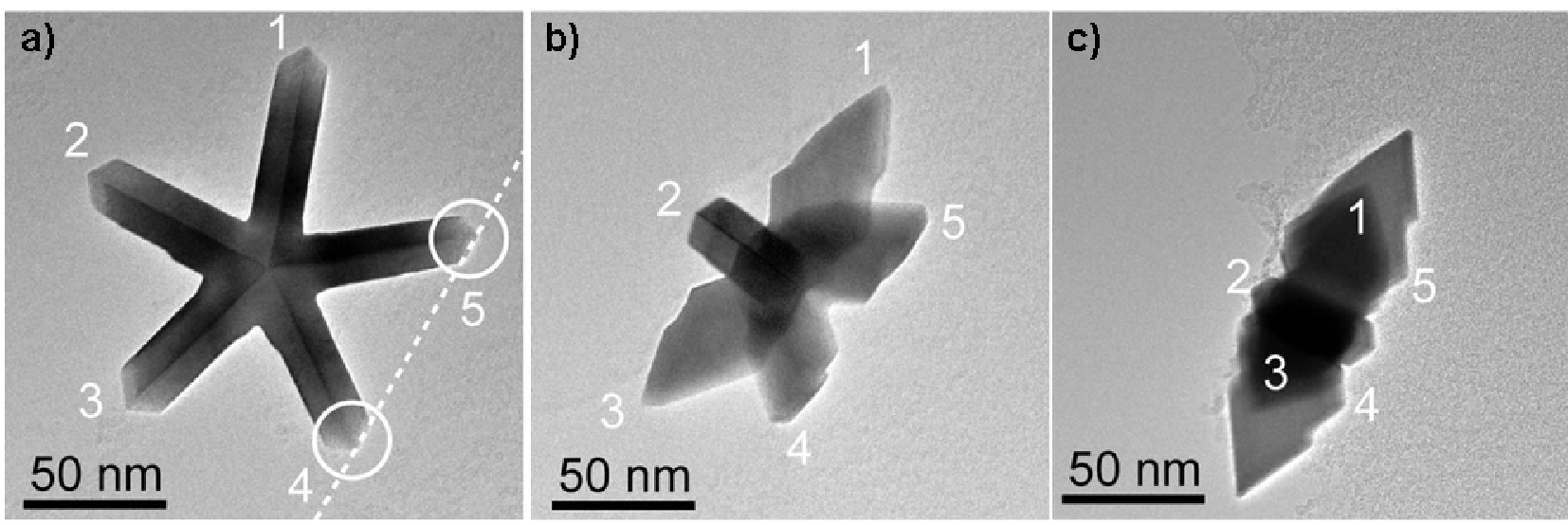

Figure S8 : Tilting series of TEM images of Pt NPs obtained for $[\mathrm{Pt}]=2 \mathrm{mM}$ at a) $0^{\circ}$, b) ca. $40^{\circ}$ and c) ca. $90^{\circ}$. The rotation axis is represented by the white dashed line in figure a. Numbers are added on each arm as a guide for the eye during the tilting. Circles around arms 4 and 5 indicate anchoring point during the tilting of the star.
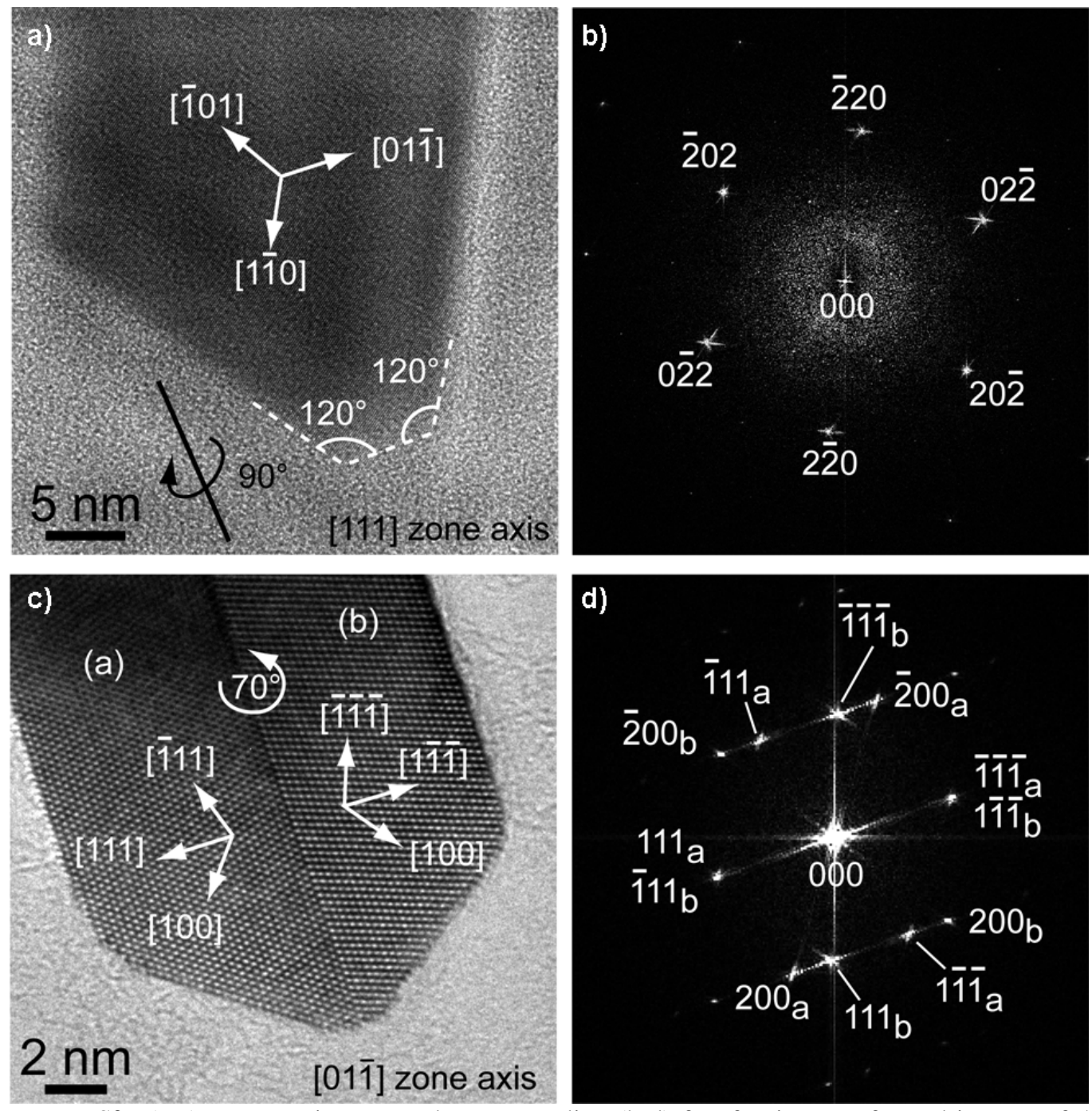

Figure S9 : (a-c) HRTEM images and corresponding (b-d) fast fourier transformed images of 5-fold star arm observed along respectively (a-b) [111] and (c-d) [01-1] zone axes. 


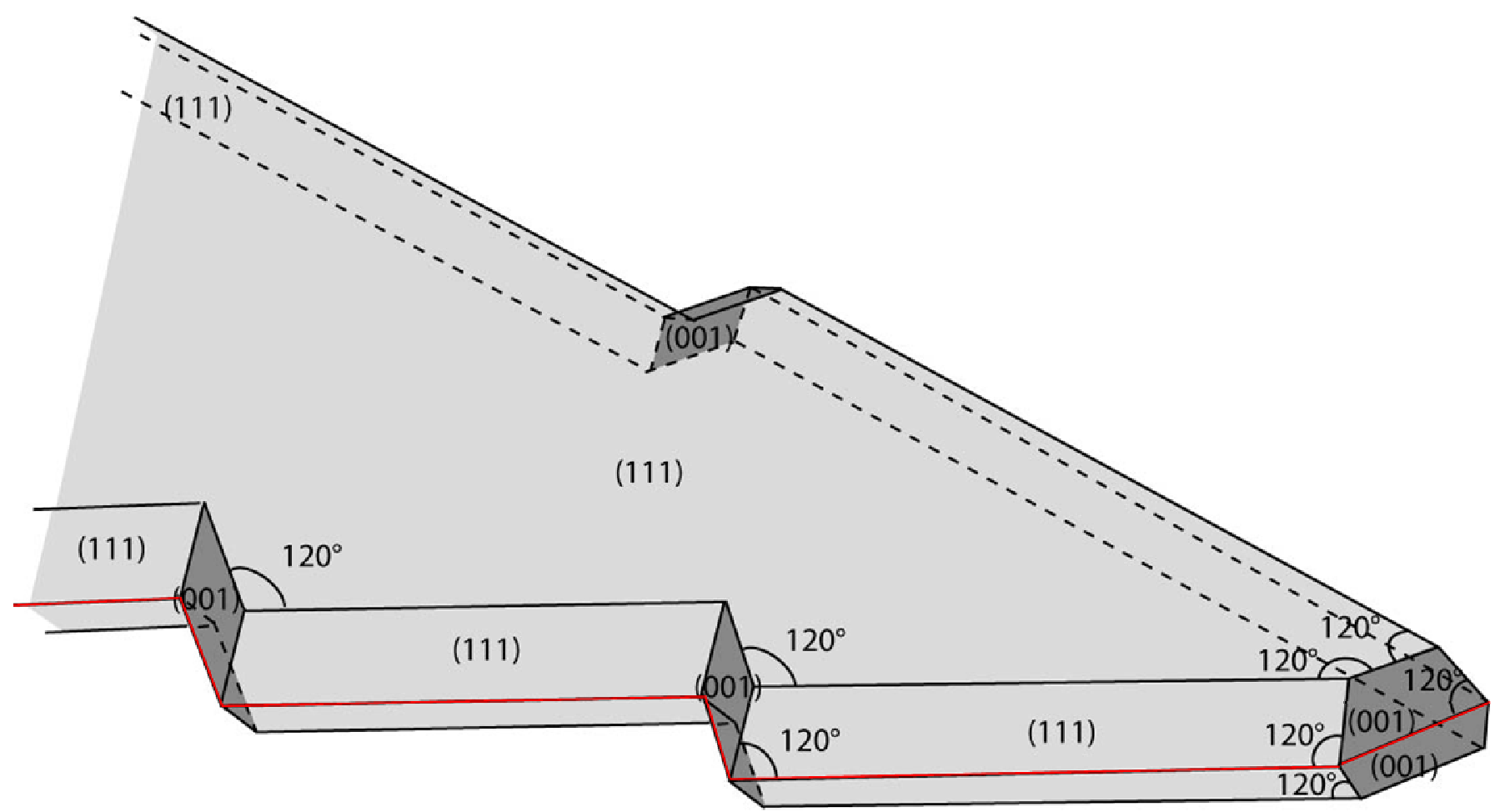

Figure S10 : Schematic view of the arms of 5-fold star displaying the corresponding faces and angles. The twinned boundary is represented in red. 

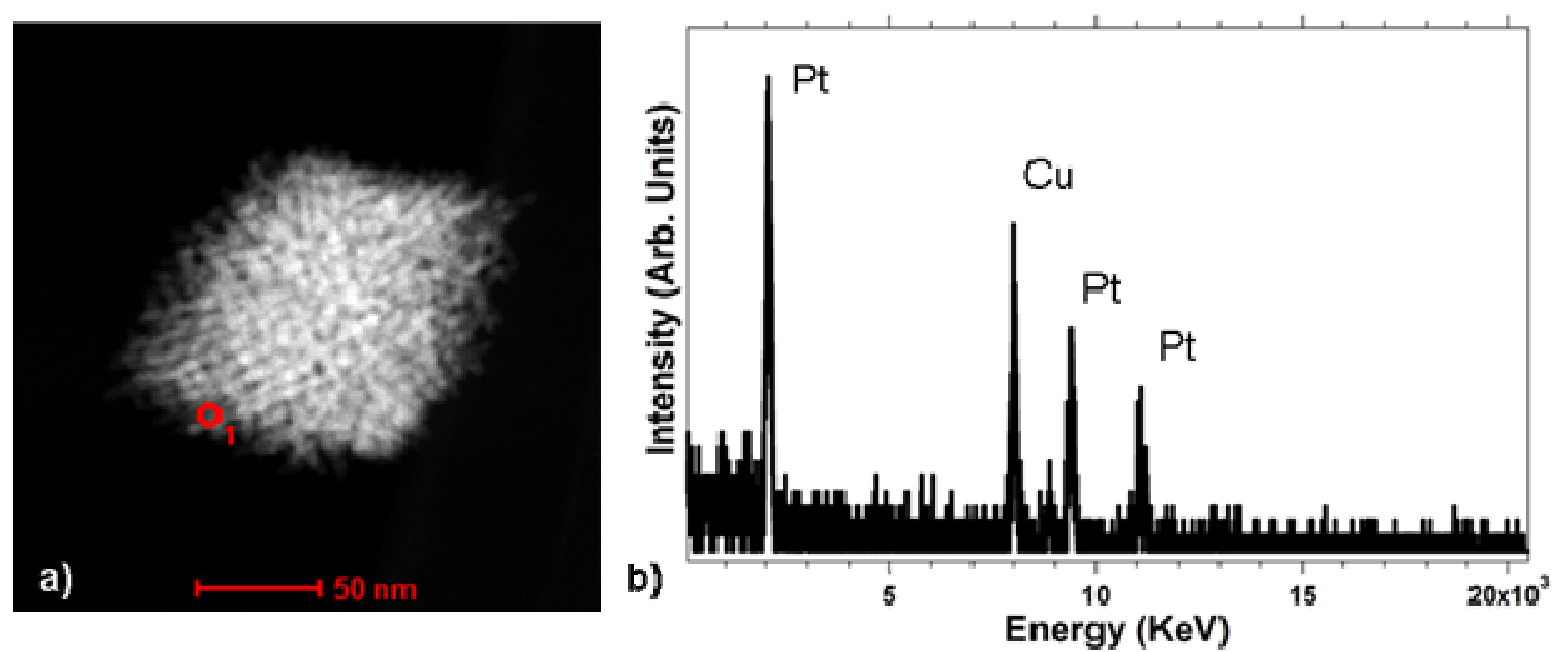

Figure S11. (a) HAADF-TEM image of a single dendrite and (b) the corresponding EDS spectrum obtained. Apart from the Cu grid, Pt is the only element detected. 


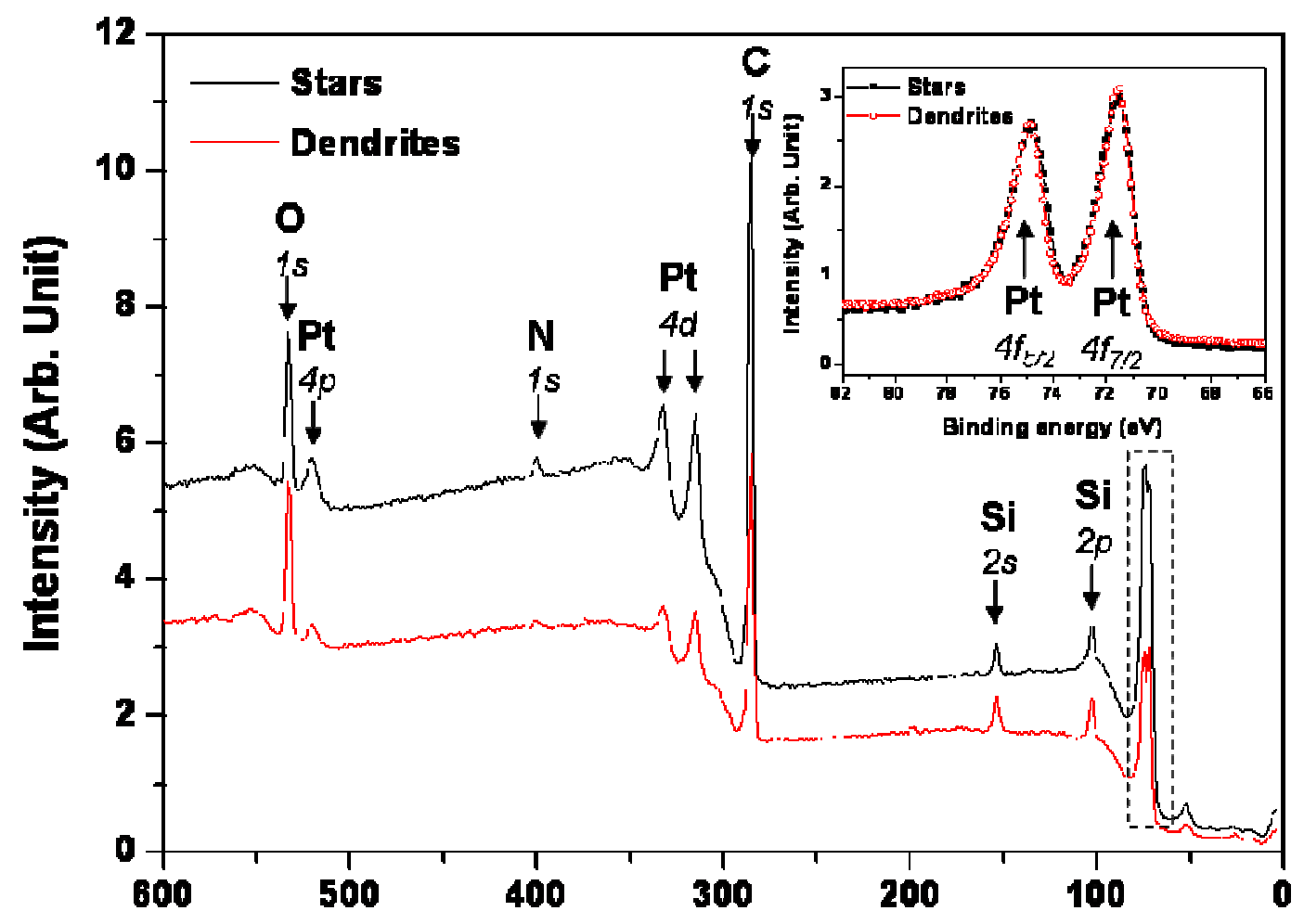

a)

Binding Energy (eV)
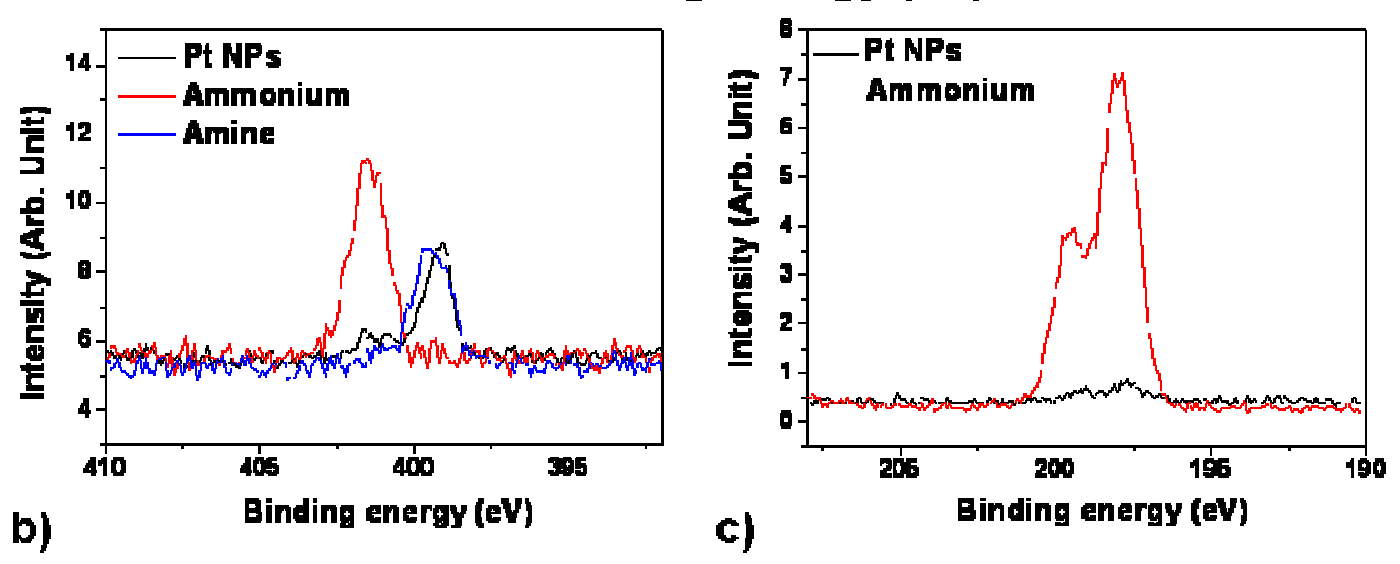

Figure S12. (a) XPS survey spectra of a) powders of Pt stars (black line) and dendrites (red line). The inset shows the Pt $4 \mathrm{f}$ high-resolution spectra. b) $\mathrm{N} 1 \mathrm{~s}$ spectra and c) $\mathrm{Cl} 1 \mathrm{~s}$ spectra. For b) and c) Pt NPs spectra (black line) and references of ammonium chloride (red line) and amine (blue line, not used for c). 

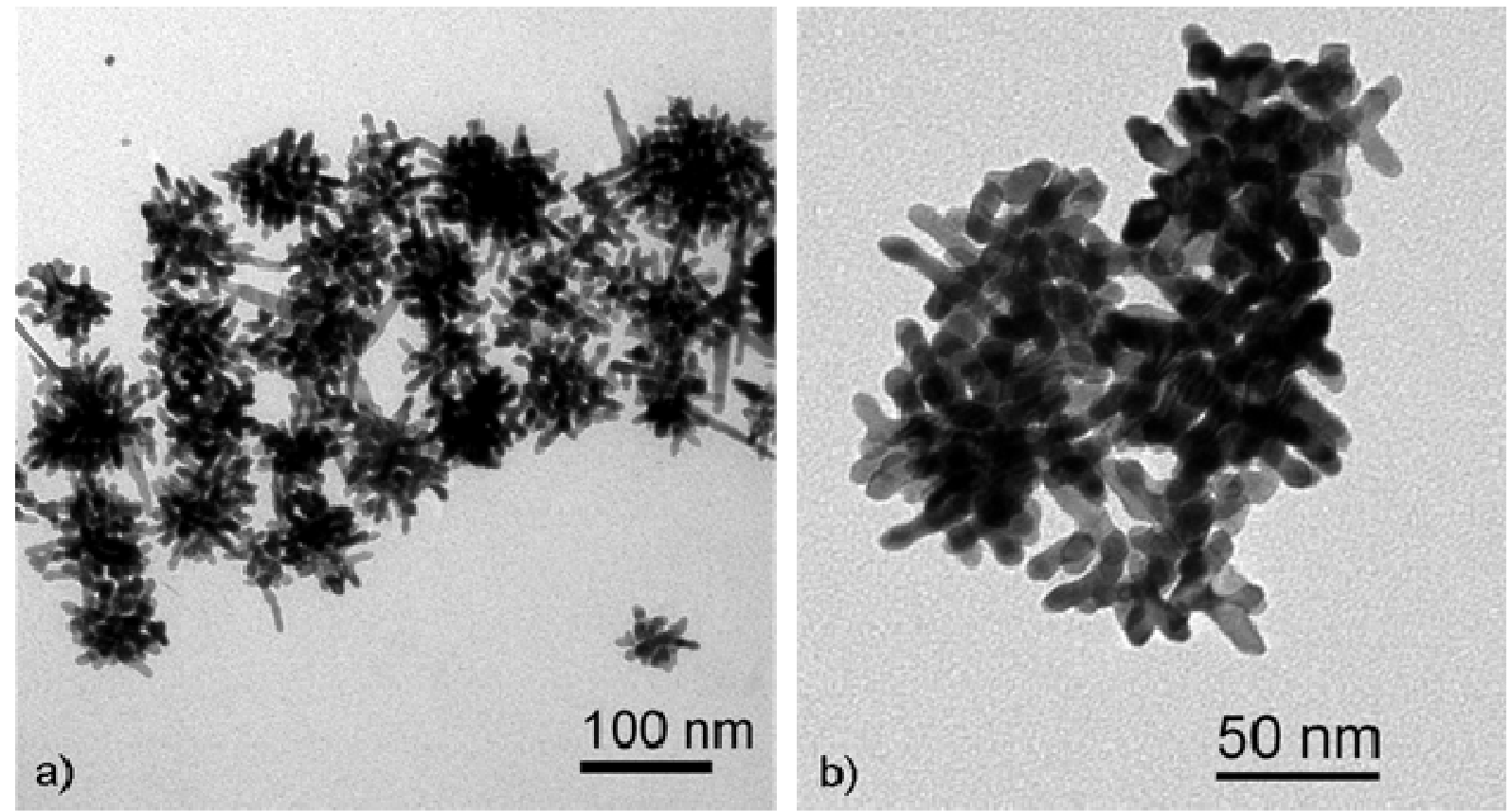

Figure S13 : TEM images of Pt NPs obtained for $[\mathrm{Pt}]=2 \mathrm{mM}, 1$ hour at $170^{\circ} \mathrm{C}, 6$ bars $\mathrm{H}_{2}$.

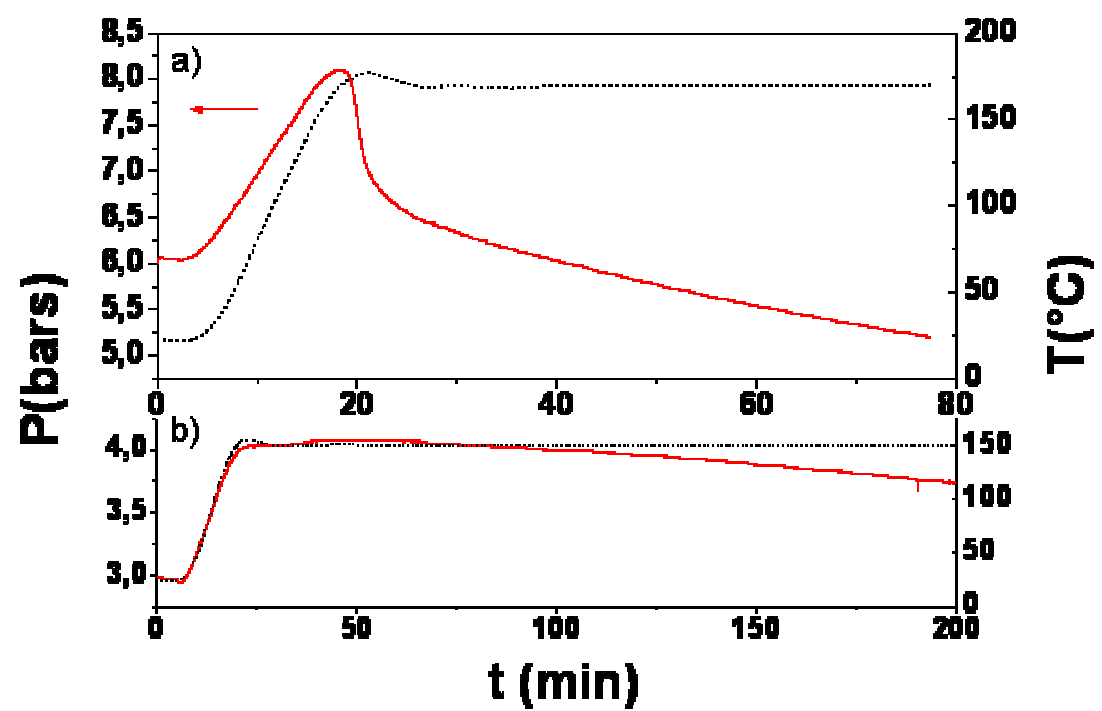

Figure S14 : Evolution of dihydrogen pressure (red solid line) and temperature (black dashed line) with time (a) for dendritic growth at $170^{\circ} \mathrm{C}$ and 6 bar of $\mathrm{H}_{2}$ and (b) for star-shape growth at $150^{\circ} \mathrm{C}$ and $3 \mathrm{bar}_{2}$. Note the different time scale used. 


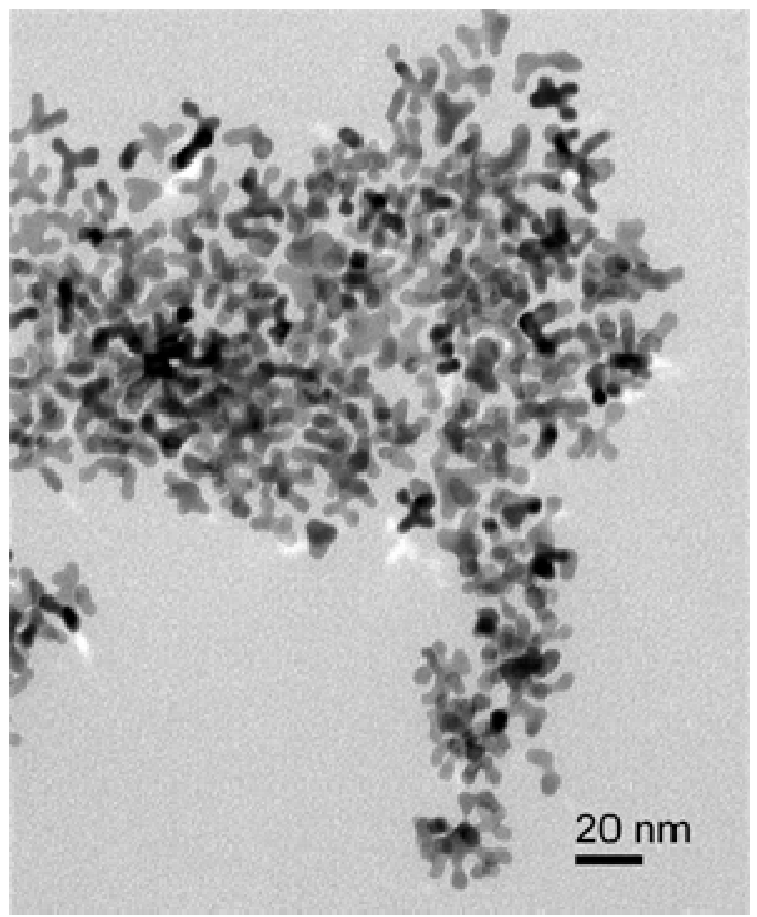

Figure S15 : TEM images of Pt NPs obtained with $\mathrm{Pt}(\mathrm{acac})_{2}$ for $[\mathrm{Pt}]=10 \mathrm{mM}$ after 1 hour at $150^{\circ} \mathrm{C}$ and 3 bars $\mathrm{H}_{2}$. 